\title{
One year's trauma in a district general hospital: injury severity and survival
}

\author{
A. P. MONTAGUE \& S. C. BROOKS
}

Accident and Emergency Department, Kent and Canterbury Hospital, Canterbur $\not$ CT1 3NG, England

\section{SUMMARY}

We studied the accident department management and survival of all seriously injured্ patients brought to the Kent and Canterbury hospital over one year. The physiological state on arrival and the injuries of each patient were coded and probabilities of survivat calculated by reference to the Trauma Score and Injury Severity Score (the TRIS\$ method). This enabled a broad comparison with North American results but also drewt attention to cases in which survival and prediction were inconsistent. We discuss ghe worth of the method as a tool for local audit of emergency care.

\section{INTRODUCTION}

The resuscitation and immediate management of trauma patients has a profound effect upon their survival. Current practice in the UK has been criticized (Anderson et al 1988). We present a review of all the seriously injured patients arriving at a districici general hospital during 1987.

The TRISS method has been used to compare actual survival with a yardstict standard of hospital trauma outcome.

The aim of this review is to analyze the results of management of severely or multiply injured patients in the Accident and Emergency Department as presently configure $\Phi$ within a district general hospital.

\section{PATIENTS AND METHODS}

This is a review of every patient with significant injury brought to the Accident and Emergency Department of the Kent and Canterbury Hospital during 1987. The

Correspondence: Susan C. Brooks, Consultant, Accident and Emergency Department, Kent and Canterburȳ Hospital, Ethelbert Road, Canterbury CT1 3NG, Kent, England. 
MTOS includes all patients admitted for greater than $72 \mathrm{~h}$ following injury, are admitted to ICU transferred from/to another hospital and all deaths. For the purposes of simplification we included only patients with a single injury with an Abbreviated Injury Score (AIS) of at least three (major injury) or of AIS two (moderate injury) in two or more anatomical regions (American Association for Automotive Medicine, 1985). We retrieved data retrospectively from hospital notes, necropsy reports and communication with referral centres where appropriate.

The Injury Severity Score (ISS) (Baker et al., 1974) is derived from the sum of the squares of the AIS of the three worst injured regions.

The Revised Trauma Score (RTS) (Champion et al., 1981; Boyd et al., 1987) is derived from the physiological measurements of Glasgow Coma Score (GCS) (Teasdale \& Jennett, 1974), systolic blood pressure and respiratory rate, the values of which are suitably weighted and then summed.

The probability of a patient's survival in an average North American trauma unit can be predicted from these scores using the following formula:

$$
P S=1 /\left(1+e^{-b}\right)
$$

where: PS represents probability of survival and

$$
b=b_{0}+b_{1}(\text { RTS })+b_{2}(\text { ISS })+b_{3}(\text { age }) .
$$

The constants $b_{0}, b_{1}, b_{2}, b_{3}$ and weights of revised trauma score components were furnished by the Major Trauma Outcome Survey (MTOS) using data from a large number of participating North American hospitals subjected to regression analysis (Copes, 1986). The coefficients differ for blunt and penetrating trauma. 'Age' is assigned the value of one if 55 years or more and zero if less than 55 years. This prediction by comparison with historic data is called the TRISS method. A concise explanation has been written by Boyd et al. (1987).

Sixty-one consecutive patients were studied. Predicted survival was compared with actual survival, and the results of accident and emergency management considered.

\section{RESULTS}

Sixty-one patients with significant injury were reviewed. Five were brought in dead and are excluded from further study; they had a non-survivable injury, most frequently brain-stem avulsion. A 55-year-old man who sustained a moderate head injury while collapsing with a myocardial infarction from which he later died has also been excluded.

Fifty-five patients are further considered. Their median age was 31 years (range 981 ); 46 were male and nine female. There were 35 victims of road-traffic-accidents and five of assaults of whom one was shot and four stabbed. Nine had fallen, three were burned and three injured in other ways.

Nine were injured in a single AIS region, 16 in two regions, and 30 in three or more regions. Thirty-one had head injuries, 28 of them with significant other injuries.

Forty-four ( $80 \%$ ) were discharged from hospital; five (9.1\%) died within $24 \mathrm{~h}$ and six $(10.9 \%)$ died more than $24 \mathrm{~h}$ after injury. 


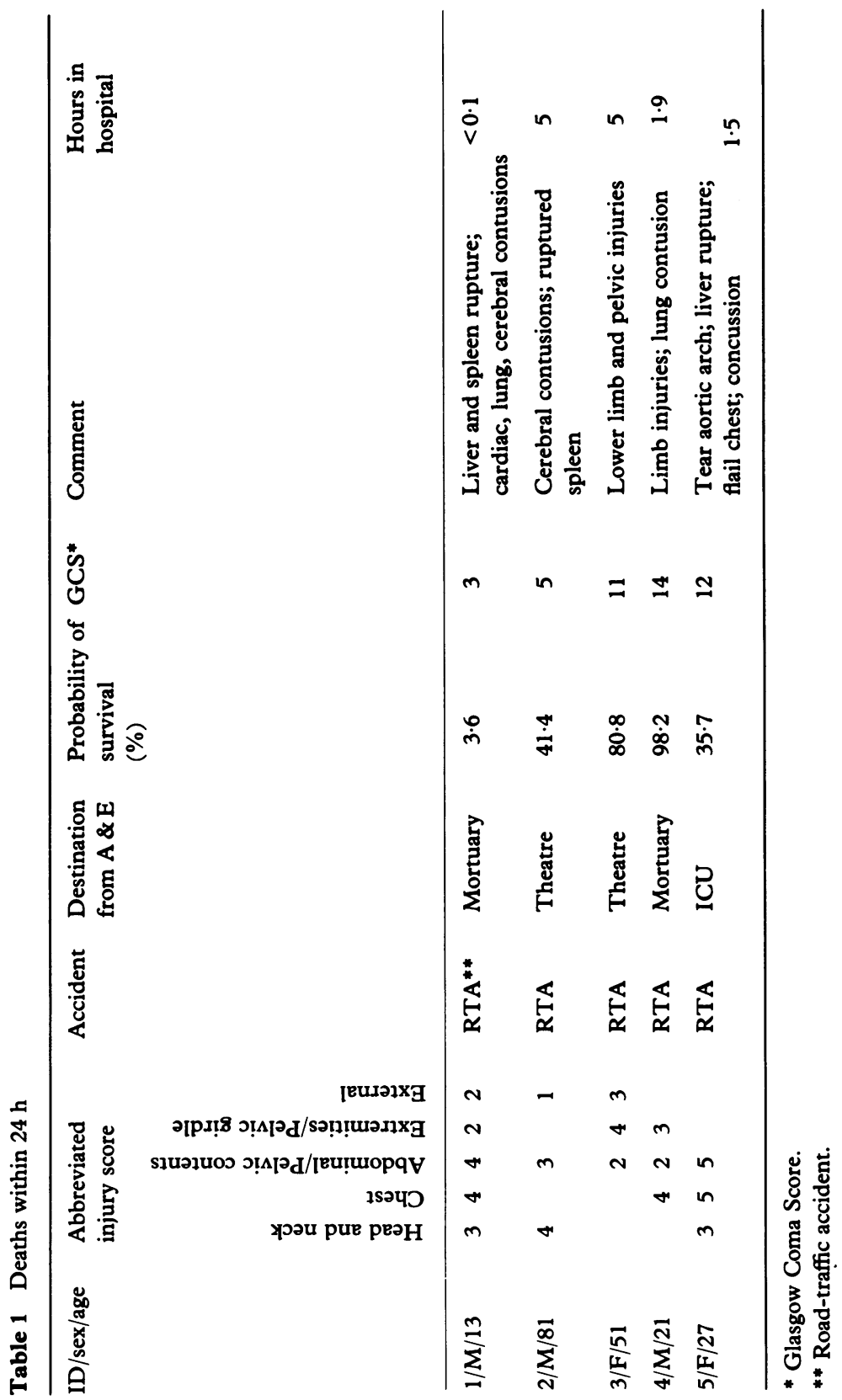




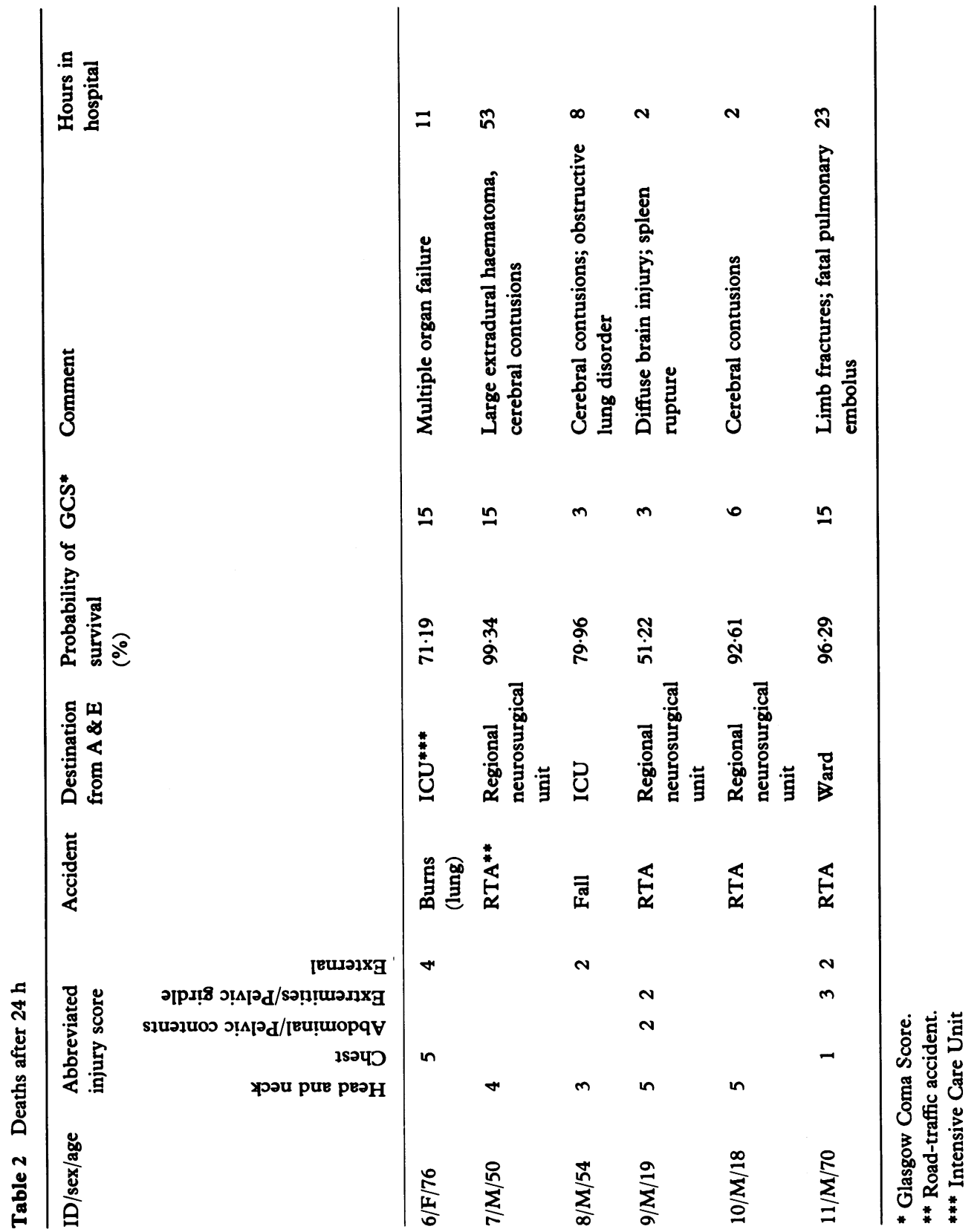


The characteristics of those who died are shown in Tables 1 and 2 . There were $11 \frac{\mathrm{\Phi}}{\mathrm{S}}$ deaths, eight of whom had a greater than $50 \%$ predicted chance of survival.

The injury severity scores and revised trauma scores were combined in the TRISS $\frac{3}{0}$ formula to give predicted probabilities of survival. These are displayed in Figure $1 \stackrel{\circ}{\circ}$ separately for each category of outcome. Means of scores are shown in Table 3.

These predictions indicate that 50 had a better than $50 \%$ probability of survival of whom eight died. Two of them died in the first $24 \mathrm{~h}$. One was a 51-year-old woman $\frac{\bar{O}}{\bar{D}}$ pedestrian ( $P S=80 \cdot 1 \%$ ) with severe and extensive lower limb and pelvic girdle injuries. She went directly from casualty to the operating theatre where she died. The other was $\varrho$ a 21 -year-old male vehicle occupant $(P S=98 \cdot 2 \%)$ with severe lower limb injuries, lung ${ }^{\text {( }) ~}$ contusions and a small liver tear who died in casualty after receiving several litres of $\odot$

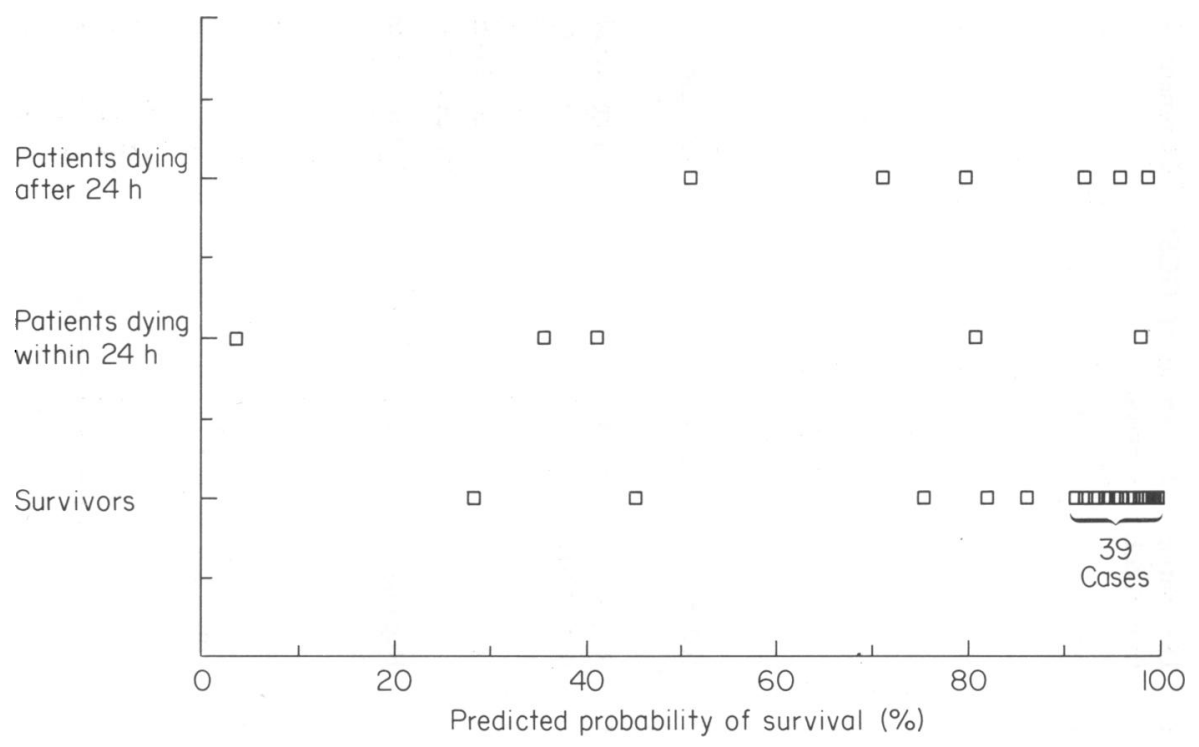

Fig. 1 Injury severity and survival.

Table 3 Mean injury scores and survival

\begin{tabular}{|c|c|c|c|}
\hline & Injury severity score & Revised trauma score & Probability of survival \\
\hline Survivors & $\begin{array}{l}18 \cdot 2 \\
(\mathrm{SE}=1 \cdot 24)^{*}\end{array}$ & $\begin{array}{l}7 \cdot 16 \\
(\mathrm{SE}=0 \cdot 17)\end{array}$ & $\begin{array}{l}93.56 \\
(S E=2.05)\end{array}$ \\
\hline Died within $24 \mathrm{~h}$ & $\begin{array}{l}36 \cdot 8 \\
(\mathrm{SE}=6 \cdot 12)\end{array}$ & $\begin{array}{l}4.92 \\
(S E=1.07)\end{array}$ & $\begin{array}{l}51.95 \\
(S E=16.86)\end{array}$ \\
\hline Died after $24 \mathrm{~h}$ & $\begin{array}{l}23 \cdot 83 \\
(S E=4 \cdot 74)\end{array}$ & $\begin{array}{l}6 \cdot 18 \\
(S E=0 \cdot 76)\end{array}$ & $\begin{array}{l}81 \cdot 77 \\
(S E=7 \cdot 5)\end{array}$ \\
\hline$S E=$ standard err & & & \\
\hline
\end{tabular}


clear intravenous fluid as well as blood. Necropsy revealed considerable pulmonary oedema. All six late deaths had a greater than $50 \%$ chance of survival. Head injury was a factor in four cases who died at another hospital.

Five had a probability of survival less than $50 \%$ of whom two survived. One of them ( $P S=28.5 \%$ ) was a 24-year-old man, stabbed in the neck with no cardiac output on his arrival. He was resuscitated and operated on immediately. The other ( $P S=45.3$ ) was a 68-year-old man who had fallen from a height sustaining bilateral flail chest and cord transection at the level of $\mathrm{T} 10$. He was intubated and ventilated immediately then treated conservatively.

We have not yet looked closely at the staff grades involved in the care of all trauma patients but it is worth noting that the two patients who died were treated by nonconsultant grades whilst the two unexpected survivors both had immediate care from surgical or accident and emergency consultants.

There was no additional mortality associated with presentation out of hours (Table 4).

The scores of the patients with head injuries are displayed in Table 5 (GCS alone vs survival) and Table 6 (PS vs survival); 24 of them survived, three died in the first $24 \mathrm{~h}$ and four died thereafter.

Table 4 Survival and time of arrival*

\begin{tabular}{llcc}
\hline & $\begin{array}{l}\text { 0900-1700 } \\
\text { Mon-Fri }\end{array}$ & Night/weekend & Total \\
\hline Survived & 8 & 36 & $44(80 \%)$ \\
Died in first 24h & 3 & 2 & $5(9 \cdot 1 \%)$ \\
Died after 24h & 1 & 5 & $6(10 \cdot 9 \%)$ \\
Total & $12(21 \cdot 8 \%)$ & $43(78 \cdot 2 \%)$ & 55 \\
\hline
\end{tabular}

*Chi-square: $4 \cdot 71$; df: 2 ; significance: $P=0.095$.

Table 5 Patients with head injuries and Glasgow Coma Score*

\begin{tabular}{lllccc}
\hline & \multicolumn{5}{c}{ Glasgow Coma Score } \\
\cline { 2 - 5 } & 3 & $4-5$ & $6-8$ & $9-12$ & $13-15$ \\
\hline Survived & 1 & 1 & 4 & 3 & 15 \\
Died within $24 \mathrm{~h}$ & 1 & 1 & 1 & 1 \\
Died after 24 h & 2 & & 1 & 1 \\
\hline
\end{tabular}

* Chi-square: $15 \cdot 29$; df: 8 ; significance: $P=0.054$. 
Table 6 Patients with head injuries and probability of survival*

\begin{tabular}{lllllll}
\hline & \multicolumn{5}{c}{ Probability of survival (\%) } \\
\cline { 2 - 7 } & $0-25$ & $25-30$ & $50-75$ & $75-90$ & $90-95$ & $95-100$ \\
\hline $\begin{array}{l}\text { Survived } \\
\text { Died within 24 h }\end{array}$ & 1 & 2 & 3 & 6 & 14 \\
Died after 24 h & & & 1 & 1 & 1 & 1 \\
\hline
\end{tabular}

* Chi-square: $31 \cdot 28$; df: 10; significance: $P=0.0005$.

\section{DISCUSSION}

In the UK trauma care is centred on the accident and emergency department which $\overrightarrow{\vec{\sigma}}$

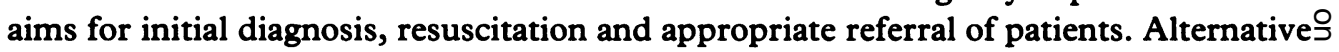
systems have been proposed including specialist units dealing exclusively and compre- $\vec{c}$ hensively with all trauma occurring in a very large region. No such proposal should be entertained or rejected without objective data.

This study is an example of the use of the TRISS method to measure thee effectiveness of an accident and emergency department. The method tests the performiance of the whole system from ambulance first aid to ward care and it is difficult isolate the effect of the accident and emergency department.

The study has demonstrated good and less than ideal trauma management. A benefit of the TRISS method is that it has identified 10 cases of interest; two survivors who $\mathbb{Q}$ were predicted to die and 8 who died while predicted to survive. The two 'successful $\overrightarrow{\vec{O}}$ cases' are of such a nature that intervention in the first hour were vital; neither was likely $\exists$ to have survived an ambulance journey to a distant specialist centre. The two 'unsuccessful early deaths' both had serious lower limb injuries and large blood loss. They are of a nature that improvement in existing technique rather than complete 3 reorganization of the system of care would have changed the outcome. Both patients could have survived a journey but competent resuscitation in the ambulance would have been crucial.

Most patients arrived outside the working day and, in contrast to the findings of $\circ$ Dearden \& Rutherford (1985), our results are slightly but not significantly better at this time. This hospital has senior accident and emergency staff available at all times.

An attempt has been made in the MTOS to provide an average standard of N management by which hospitals may compare their results. This is the $Z$ statistic (Boyd et al., 1987), which gauges the difference between the actual number of deaths and those predicted using the MTOS data. It is calculated by the formula:

$$
Z=\frac{D-\Sigma Q i}{\sqrt{(\Sigma P i Q i)}}
$$


where

$D=$ actual number of deaths

$Q i=$ predicted probability of death per patient $(1-\mathrm{Pi})$

$\Sigma Q i=$ predicted number of deaths

$P i=$ predicted probability of survival $(100 \%=1)$

When $Z$ takes a negative value it indicates overall survival better than expected in comparsion with North American figures and conversely a positive value indicates a worse result.

The $Z$ statistic for the 11 deaths in this series has the value of +2.58 meaning more deaths occurred than predicted. A further formula expresses similarity between populations as the $M$ statistic (Boyd et al. 1987) with a range from one (perfect match) to zero (no similarity). The patients in this study were more severely injured than the baseline (MTOS) population and $M$ is 0.698 , it is also a very small number of patients. Therefore $Z$ may be less reliable.

The Glasgow Coma Score (GCS) is a well-established predictor of survival and outcome in head injuries. In our head-injured patients, the TRISS probability of survival (which incorporates the GCS) is significantly related to simple survival $(P=0.0005)$. The Glasgow Coma Score is less well related to survival $(P=0.054)$; however, only three patients had uncomplicated head injuries. This suggests that the presence of other injuries may have had some deleterious effect on head injury outcome.

The majority of late deaths in our series result from head injury; it is submitted that in some of these cases predicted probabilities of survival may be unrealistic as in Case 10 where a GCS of six with no other injury gave an expected survival of $92 \cdot 61 \%$. From neurosurgical data (Miller et al, 1981) the expected survival would be closer to $70 \%$. Case 8 is another example where a 54-year-old patient with a GCS of 3 is attributed a $79 \%$ chance of survival; neurosurgical data would predict death more likely than survival. We do not seek to avoid the criticisms that peripheral centres have received over the management of head injuries (Jeffreys \& Jones, 1981; Miller et al., 1985; Richards, 1988): indeed in Case 7 the diagnosis of an extradural haematoma associated with cerebral contusions was delayed. The TRISS method may now need to take better account of the extensive data available on the outcome of head injuries but these deaths highlight the problem of trauma care in centres without easy access to neurosurgical support.

Another difficulty found with the TRISS method was that a high probability of survival could be predicted despite numerous serious injuries if confined to a single AIS region. The anatomical score for a region cannot, by definition, exceed that of the worst single injury in that region. It may result in an unrealistic prediction where many injuries lie within one region as in case 4. A single femoral fracture earns the same score as multiple limb fractures. Spence et al. (1988) point out that part of the difficulty of the TRISS method in predicting head injury survival is due to this limit of score within one region. This is also likely to explain the accepted poor survival from burn inhalational injury but the high TRISS probability of survival. The method also takes no account of pre-existing disease.

It is vital to have an objective standard by which a trauma system may be judged. The 
TRISS method is derived from analysis of more than 80000 patients in the MTOS. It is a refinement of the AIS and is capable of further refinement.

Some studies such as that of Anderson et al. (1988) are based on 'preventable deaths' $\frac{3}{\mathrm{C}}$ taking no account of the severity and type of injuries in surviving patients. Criticism? aimed at trauma care based on anecdote and some bad cases is of no help.

Audit of trauma care in any centre, including our own, must be based on assessmento of all trauma cases treated, deaths and survivors. Since the TRISS method is based on a $\frac{\bar{O}}{\bar{\sigma}}$ large group of patients with the same 'problems' of isolated head injuries and multiple $\frac{\overline{\frac{\rho}{\sigma}}}{\bar{\Phi}}$ injuries in one category, it is a useful method of looking critically and honestly at $\varrho$ methods of trauma care, even in a small series such as this. We would recommend its use ${ }^{\infty}$ to other district general hospitals seeking to monitor their own performance.

\section{REFERENCES}

American Association for Automotive Medicine. The Abbreviated Injury Scale, 1985 Revision. Arlington 윽 Heights, IL. 60005, USA.

Anderson I. D., Woodford M., de Dombal F. T. \& Irving M. (1988) Retrospective study of 1000 deaths from injury in England and Wales. British Medical fournal 296, 1305-8.

Baker S. P., O'Neill B., Haddon W. \& Long W. B. (1974) The injury severity score: a method for describing patients with multiple injuries and evaluating emergency care. fournal of Trauma 14, 187-96.

Boyd C. R., Tolson M. A. \& Copes W. S. (1987) Evaluating trauma care: the TRISS method. fournal Trauma 27, 370-8.

Champion H. R., Sacco W. J., Carnazzo A. J., Copes W. \& Fouty W. J. (1981) Trauma Score. Critical Cd䅠 Medicine 9, 672-6.

Copes W. S. (1986) Personal communication. In: RE: Major Trauma Outcome Study to Participating Trauma centers.

Dearden C. H. \& Rutherford W. H. (1985) The resuscitation of the severely injured in the accident and emergency department; a medical audit. Injury 16, 249-52.

Jeffreys R. V. \& Jones J. J. (1981) Avoidable factors contributing to the death of head injury patients in general hospitals in the Mersey region. Lancet 2, 459-61.

Miller E. S., Neoptolemos J. P., Aitkenhead A. R. \& Fossard D. P. (1985) Management of severe head injuries in a non-neurosurgical trauma centre. Fournal of the Royal College of Surgeons of Edinburgh 30, 82-7.

Miller J. D., Butterworth J. F., Gudeman S. K. et al., (1981) Further experience in the management of severe head injury. Fournal of Neurosurgery 54, 289-99.

Teasdale G. \& Jennett B. (1974) Assessment of coma and impaired consciousness: a practical scale. Lancet 2, 81-4.

Richards P. (1986) Severe head injury: the first hour. British Medical fournal 293, 643.

Spence M. T., Redmond A. D. \& Edwards J. D. (1988) Trauma audit-the use of TRISS. Health Trends 20, 94-7. 